\title{
Value and Use of English as a Global Language in a Bulgarian Higher Education Internationalization Context
}

\author{
Noparat Tananuraksakul ${ }^{1^{*}}$ \\ ${ }^{1}$ Rangsit University, Thailand \\ "Correspondence: noparat.t@rsu.ac.th
}

\begin{abstract}
Both internationalization of higher education and use of English as a global language (EGL) coexist, for the latter is a vital tool to attain the former and vice versa. Although the former came into existence in non-native English-speaking countries in Europe, and the latter became the major medium of instruction at universities with the de facto 'extraterritorial' lingua franca, research into international students' issues has mainly been conducted in English-speaking countries. This paper, therefore, aims to explore such value and use of EGL in a higher education internationalization context in Bulgaria. With the qualitative research approach, two themes emerge, answering two research questions. The results collected from 13 students from European and former Soviet backgrounds offer insights into linguistic, cultural, and psychological challenges international students tend to encounter as well as determinants that impact their adjustment.
\end{abstract}

Keywords: use of English as a global language, non-native English students, higher education internationalization, World Englishes

\section{Introduction}

The twenty-first century has witnessed substantial human mobility, both legal and illegal, plus temporary and permanent. This mobility derives from poverty, political conflicts, civil war, the pursuit of education, international collaborations, and marriage across cultures; people seeking better pay, better work, better lives. In recent years, the pursuit of higher education abroad has attracted more than five million students to study in different destinations, which not only indicates campus diversity and internationalization (Bista et al., 2018) but also changes the global higher education landscape (Wells, 2014). By 2025, the number of international students worldwide is predicted to reach 15 million (Altbach, 2016). This phenomenon is considered as internationalization of higher education.

Received March 12, 2020; revised July 19, 2020; August 7, 2020; accepted October 1, 2020; electronically published March 2, 2021 
Inescapably, internationalization of higher education coexists with use of English as a global language (EGL). While the former helps to drive the attainment of EGL for international communication, knowing English advances a person or a system's ability to become internationalized. Although the former came into existence in non-native English-speaking (NNES) countries in Europe (Altbach, 2015), and the latter became the major medium of instruction at universities (Yano, 2018) with the de facto 'extraterritorial' lingua franca (Seidlhofer, 2012), research in relation to international students' issues have mainly been conducted in English-speaking countries (Khanal \& Gaulee, 2019). Within this debate, it is worth exploring the value and use of EGL in a higher education internationalization context in Bulgaria, in which American educational systems and English as media of instruction and communication are adopted. It attempts to answer these two research questions: (a) the way in which NNES students value English at the exclusion of other languages; and (b) the way in which they experience the use of EGL in this context.

\section{The Premise}

Tertiary institutions in Europe are seen to highly focus on internationalizing their programs, followed by North America, the Middle East, Latin America, and the Caribbean (Kreber, 2009), and this accords with the Organization for Economic Cooperation and Development's (2013) report that the top two continents with a great share of hosting university students from other nations were Europe (48 percent) and North America (21 percent). While this internationalization particularly came into existence in Europe through the advent of the European Union and the recognized need to use a higher education system to promote the flows of international students (Altbach, 2015), the target university was uniquely founded under collaborations with the U.S., and Bulgarian government. Through its policies, practices, and academic systems, the target university has enjoyed not only the flow of student mobility from over 40 different countries but also student development for global citizenship by international faculty members.

One of the key components of global education is English. Approximately, 1.8 billion people speak English, making it the world's third most spoken language because it is highly valued as a necessity for better opportunities in employment, access to knowledge, higher education and international communication (Corradi, 2017). As such, English attains its global status of a commodity that has an effect on school curricular and cultures (Spring, 2009) in many NNES countries in which English becomes a compulsory subject learned as a foreign language at school. In Europe, English as a foreign language (EFL) is most taught at all levels of school, and the number of children who learn English is still growing, especially in Bulgaria, the Czech Republic, Hungary, and Slovakia (Seidlhofer, 2012). 
The use of EGL also enables NNES people with the ability to communicate with others in the language to have a global share in power of collaboration and competition (Tananuraksakul, 2010). In parallel, Manakul (2007, p. 161) concluded in her research that "for a country whose language is used only within its boundaries, using English in higher education has certain internationalization effects" in attracting excellent students from other countries. It can be said that English is deemed essential and valuable, especially in contexts where people learn EFL or use it as a non-native speaker. Countries (e.g., Bulgaria, Croatia, Georgia, Kazakhstan, and Ukraine, to name but a few, which are the participants' countries of origin in this study) are not excluded. It can imply that NNES students obtain extrinsic and/or intrinsic motivation in learning English.

The aforementioned proposition is substantiated in Europe as Seidlhofer (2012) points out that English rather than other languages has been part of all European citizens' lives. Their daily activities are influenced by American popular culture, such as watching MTV and CNN and listening to English pop lyrics. Take Bulgaria an example. New generations of this country are fully aware of advancements of use of EGL in their future career, life-long learning, and mobility (Vasileva, 2008), and they tend to learn the language through watching cartoons, movies, and BBC and CNN news, playing online games and singing with lyrics and even use English as a part of their daily lives (Slavova, 2018, p. 89). As a result, "Euro-English" has come into being (Yano, 2018, p.100), a type of "pidgin English" mostly used in the European Union. The implication is that European students from NNES backgrounds are contextually confident in using English and possess positive attitudes toward and intrinsic motivation in learning the language.

Khanal and Gaulee (2019, pp. 569-570) proposed that all NNES students in English speaking countries must experience: culture shock, feelings of discomfort, frustration, and confusion; issues relating to finance, psychology, living, and socio-culture; and obstacles to use English for social and academic purposes. These challenges derive from unfamiliarity with sociocultural and linguistic differences, which in turn negatively impact their psychological well-being (Tananuraksakul, 2009b); for instance, they may experience academic culture shock once they find the learning environment at university, education system, lecture styles and relationships between students and lecturers difficult to adjust to (Li et al., 2010), which can be understood through Hofstede's (2019) cultural dimensions, namely, individualism, collectivism, and power distance. For example, in order to show social harmony and respect to teachers, Bulgarian students have collectivistic and high power distance backgrounds, so they culturally value group relations, passive learning behaviors in the class, and face negotiation. These 
values are opposed to Americans whose cultural backgrounds are more of individualism and low power distance.

Furthermore, in intergroup communication among native and non-native English speakers (students and lecturers), it is common for them to communicate in "World Englishes", the term Kachru (1992) coined in the 1970s to describe English varieties socio-linguistically used by speakers of native, near-native and non-native English. Almost one-third of speakers from the 13 NNES countries of the European Union think they can converse with confidence in English with culturally different others (Anderman \& Rogers, 2005, p. 24). Intergroup communication via World Englishes can break down if there are different levels of English competence as well as pronunciation-based misunderstanding as Jenkins (2002) found that "certain pronunciation deviations, particularly in consonant sounds, vowel length and the placing of tonic stress" (p. 91), caused an NNES person's pronunciation to lack mutual intelligibility to an NNES interlocutor. In addition, unfamiliarity with certain varieties of English and ignorance of speech and cultural accommodation can result in lack of mutual intelligibility (Tananuraksakul, 2009b, 2012), which can cause World Englishes shock and repetition shock, which refers to emotional impacts by exposure to alien varieties of English and repetition when expressing something (Tananuraksakul, 2009b, p. 49).

This study is based on the premise that apart from the globally recognized status of English, NNES students with collectivist and hierarchical cultures (collectivism and 'high power distance') likely value English language learning because of parental, social, or personal aspirations and negotiate face in group interactions. Face intersects with identity in the conversation since the former represents how individuals want to present the latter (Goffman, 1967), which is something individuals construct and negotiate all of their lives through their interactions with others. Identity is hence multifaceted (Thornborrow, 2004; Ting-Toomey, 2005) in that people often moderate their identity in accordance with the social situation they engage in and their goal for interactions. NNES students' social and academic journeys in the present context share similarities with previous research mainly conducted in English-speaking countries where individualism and 'low power distance' are culturally exercised.

\section{Methods}

The present study is considered phenomenological since it explores NNES students' personal experiences (Johnson \& Christensen, 2012) in value and use of EGL in the present context. Unstructured in-depth interview was opted for data collection, as it allowed them to provide insightful information (Creswell, 2015) about their experiences. The target group was undergraduate students from NNES 
backgrounds studying at a recognized Western university in Bulgaria employing American educational systems and English as media of instruction and communication.

Participant recruitment started after the University Ethics Review Committee (Human Research) had approved the ethical aspects of this study. Invitations to voluntarily participate in this study were posted on student boards in the main buildings where the target group could easily notice. Thirteen students from European countries and former Soviet Republics signed up for face-to-face interviews, and each interview took about 30 minutes. Examples of unstructured questions are:

(a) why are you studying English?

(b) have you experienced any linguistic and/or cultural barriers?

(c) can you share those experiences?

(d) how did you feel about those experiences?

During the interviews, the researcher ensured all the participants of confidentiality and took notes instead of tape recording so that they felt at ease to share their experiences. The interview data were then transcribed and validated by each participant who was requested to check, correct and approve the transcripts through email. After that, the transcripts were analytically segmented and coded so as to identify themes (Creswell, 2003; Johnson \& Christensen, 2012) in relation to the research questions. Through this process, the researcher first highlighted the segments of data into meaningful units with different colors, coded them with category names, and identified all related categories. Finally, two themes emerged, which answered the research questions.

One of the participants was male while 12 were female. Seven were from Bulgaria while the rest were from Georgia, Ukraine, Croatia, and Kazakhstan. They all had to pass a standardized English test for university admission. The duration of their English study ranged from 6 years to 16 years, and all of them indicated in Table 1 are adequately competent in English.

\section{Table 1}

Participants' Demographic Information

\begin{tabular}{c|c|c|c}
\hline Student & National & $\begin{array}{c}\text { Duration of } \\
\text { study of English (years) }\end{array}$ & English Proficiency Level \\
\hline 1 & Bulgarian & $11-12$ & IELTS score band $=8.0$ \\
\hline 2 & Georgian & Since first grade & TOEFL $=100+$ \\
\hline 3 & Bulgarian & $14-15$ & IELTS score band $=8.0$ \\
\hline 4 & Croatian & 12 & IELTS score band $=8.0$ \\
\hline
\end{tabular}




\begin{tabular}{c|c|c|c}
\hline 5 & Bulgarian & 10 & IELTS score band $=7.5$ \\
\hline 6 & Bulgarian & Since 2-3 years old & Cambridge - C1 \\
\hline 7 & Bulgarian & 9 & CAE \\
\hline 8 & Ukrainian & 16 & CAE $=$ B \\
\hline 9 & Bulgarian & 14 & IELTS score band $=6.5$ \\
\hline 10 & Kazakhstani & 5 & TOEFL $=575$ \\
\hline 11 & Ukrainian & 8 & Preparation for IELTS \\
\hline 12 & Bulgarian & Over 10 & TOEFL - unindicated result \\
\hline 13 & Georgian & 6 &
\end{tabular}

Findings

Data qualitatively collected from 13 undergraduate students from NNES backgrounds were grouped into two themes that answered the research questions.

\section{Key Research Theme One: Value of English at the Exclusion of Other Languages}

It appears that in Bulgaria and Georgia, English is a compulsory subject to study at school, but it does not mean that all students can be fluent in the language. Students from these two countries particularly raised this issue. Students $2,5,6,9$, and 12 expressed their voice in a similar manner to say that everyone in their country was required to study English, but not everyone could speak it. Student 5 additionally explained this dichotomy by saying, "the learning environment is not competitive enough and teachers don't have time to pay attention to every student...so going to a private lesson helps us learn better..." Students 6 and 9 shared another insight into their homelands as the former mentioned that "my friends and I talked and came to a conclusion that it would be strange not to know Bulgarian and English...everything on the Internet is in English so we have to learn...it is part of us to speak English..." The latter says "here in Bulgaria, English is the most studied foreign language... without English it creates barriers..."

Parents also have a great impact on some students' motive in learning English, which reflect the collectivistic culture embedded in them. Students 1, 6 and 9 were encouraged to learn English by their parents when they were young. Student 1 says "my mother made me study it. I think she knew the importance of the language," while Student 9 stated "I started watching English cartoons from Fox's kids channel and my parents noticed that I could pick up English words quickly, so they supported me to study English with a private tutor." Student 6 elaborated that "my mother was proud of me when seeing me answering the phone in English at 2-3 years old and wanted me to learn English to open the world." 
Student 4, meanwhile, studies English due to the parents' work as diplomats, moving around from Italy to Australia to Egypt to Croatia and now to Bulgaria.

Culturally and socially speaking, students may be motivated to learn English, but it actually requires personal aspiration or intrinsic motivation to learn the language successfully. Students 1, 3 and 9 always want to study English, so in their free time, the first two learn the language from American television shows, and the last practices English through video games. Student 1 loves England and has "passion for English." Student 3 has spent summers in America through a work and travel program since 2016, for five months each time, saying that "knowing English opens other doors for me...to meet new people, explore the world, go and live in a new country." Student 12 "likes English...it is like music to me. The perception of English being music motivates me to learn the language."

\section{Key Research Theme Two: Linguistic, Cultural and Psychological Challenges}

The participants experience cultural and linguistic barriers. Student 2 was not confident in writing and speaking skills in the first year of study, saying:

I preferred not to say something to senior students because I was afraid to make a mistake or sound stupid to them...I was unconfident in my own English...Once I engaged with more people and the club [I belong to], I began to interact with everyone...I also had a problem with academic writing and I blamed it on English itself...English was stupid or silly...there were not enough words in English to express myself. Actually, there's not enough practice but I could overcome the problem by reading a lot...readjust to American writing styles through professors' comments about how to choose the right words for my ideas.

Students 10 and 12 shared something in common as they had problems in writing. The former emphasized that "my writing skill is not good enough as I still translate from Russian to English and receive a professor's comment about the needs to improve my writing..." The latter said:

I have no problem with communication with others but if I make a mistake, I feel down and try to control it. Sometimes, I feel stressed, but practicing a lot helps me feel better. I have a weakness in my writing, and it's hard for me to write even in my own language because it's like a document. I feel that I may make a mistake on the document and I feel insecure...it's like taking a test.

Unlike Students 10 and 12, Students 11 and 13 experienced barriers in English speaking, but not in their writing skills. The former thought "speaking was problematic due to lack of self-esteem," but writing was "good enough. I compensate it with my speaking problem, so I feel ashamed and stupid, lowering my confidence and self-esteem when I read something and don't understand it..." The latter 
was not confident because close friends kept correcting this person's English but having "a little more confidence" when a professor commended on the paper that "it was written well with good content although grammar was incorrect."

Students 5, 7, 9, and 13 encountered a similar situation. Both Students 5 and 13 in particular mentioned that professors from Italian, Spanish, Bulgarian and French speaking backgrounds spoke English with "a heavy accent", and it took time to be used to it for Student 5. It only took "a few days" for Students 7 and 9 to be familiar with the heavy accent. However, for Student 13, it was a challenge to overcome the barrier because:

it was hard to understand a fellow countryperson's unclear spoken English and what the professor from [a] French-speaking background said and concentrate on the lecture...once I was ashamed of my answer to the question...it was not the answer...my mind was somewhere else...lost...so when I was asked for the answer, it was wrong...I lacked confidence but not selfworth.

Student 13 explicitly added that students and professors were also from NNES backgrounds, and everyone came here to learn, so "I tried to get used to the English varieties."

Different styles of teaching and learning that Student 7 was previously used to appear to impede the adjustment to a new environment at the university because "I experience culture shock, which makes me feel insecure...I am used to formality in almost [all] situations...it's less formal here...it's hard for me to adjust...students are highly encouraged to participate in the classroom but not in Bulgarian culture."

Students 5, 7, and 13 did not enjoy being asked to repeat what they said and negatively impacted them. Student 5 "felt a little ashamed and frustrated," while Student 7 felt "ashamed" when being asked by native or near-native English speakers at a part-time job to say something again. Student 13 lacked "confidence and felt excluded when two close friends laughed at my English and I was asked to repeat what I said." However, Student 7 would feel fine "if non-native English speakers ask me to say something again, because I can relate to them, how we have to go through the same process of learning English."

Both Students 5 and 7 experienced awkward moments in approaching their professors. When it came to discussing something with a professor from native English-speaking backgrounds both appeared to feel apprehensive and in turn lost confidence and risk-taking in communication. The former would feel "nervous, worried and stressed which affect my confidence and self-worth" whereas the latter would "lack confidence and slightly lose dignity, for they both thought the same way about their 
English - that they were being "judged." Student 6 "would feel relaxed to express myself if I feel close to them like the American professors...it's a matter of a relationship or whom I'm talking to." There was nothing else worrying Student 5 except saying something in the classroom that "would make me look stupid." When this person had such a feeling, consultations with the professor after class would be the choice due to the "feeling of shyness to ask and avoidance to disturb the lecture time...feeling annoyed when some students ask many questions just to receive attention or favors from professors."

In the classroom, Student 4 feels confident and secure in using English because "people speak English...there's always someone who speaks well or better than me...in this situation, I am brave to express myself in English and feel more accepted by classmates and professors." Outside the classroom, however, Student 4 does not feel so confident and lacks dignity because:

everyone treats me like a stranger...people at the restaurant would give me an English menu instead of Bulgarian menu...speak English not Bulgarian to me...charge me a double price...I feel unconfident in my English outside the classroom because people don't speak English to me.

Student 5 encapsulates the willingness to interact with culturally different others because "I am motivated to speak more clearly and would try to explain my expressions better or say 'whatever' or stay silent."

\section{Discussion}

Since English is an attractive instrument specifically empowering non-native students (Tananuraksakul, 2015, p. 149), learning it as a foreign language can be a pleasure or a pressure depending on one's situation. Theme one answers the first research question because it marks the participants' value of English at the exclusion of other languages, which manifests in their positive affect, namely extrinsic and intrinsic motivation in learning the language with a good attitude. Arnold and Brown (1999, p. 1) regard affect as "aspects of emotion, feeling, mood or attitude which condition [language learners'] behaviors" in learning English in the present context. Positive affect strengthens them to value and study the language and vice-versa.

Both social context of learning and using EFL in the participants' homelands and the status of English as a language of globalization and internationalization appear to be the initial reasons why the participants have studied English. Five participants from Bulgaria and Georgia witness this proposition and find themselves to be motivated to learn English. As English provides a medium for understanding ideas and innovation around the world on the Internet (British Council, 2013), two of those five from Bulgaria, strongly assert that evidently young generations like them view English highly as a vehicle of advancement and globally shared power in their home country. 
The assertion firstly aligns with Seidlhofer's (2012, p. 359) analogy that "having English in Europe has become a bit like having a driving license: nothing special, something that most people have, and without which you do not get very far." Secondly, Slavova's $(2018$, p. 88$)$ research outcomes show that 28 out of all 62 Bulgarian students consider English as a tool for global business, travelling and sharing information. Thirdly, a report by EF Education First says that from an online survey by 1.3 million, out of 88 NNES countries, Bulgaria has made its way to reach the country ranked twenty fifth in the world for its high level of English skill (The Sophia Globe, 2018). The analysis also suggests that students from Bulgaria and Georgia tend to value English and socially aspire to study English due to its global status.

There is no doubt that parents' advice and career in diplomacy could make a great impact on their children's motivation, reflecting a collectivistic culture embedded in their being and thinking. Three participants from Bulgaria were encouraged to learn English by their parents when they were young. These findings appear to resonate with 28 Bulgarian participants in Slavova's (2018) research into attitudes toward English as a lingua franca. Several of them were attracted by English cartoons during childhood and gradually started to comprehend the language, for example, one said "...[my interest toward English] all began [before 4 years old] with my love for cartoons and through watching them exclusively I began to acquire the basics of the language (p. 89)". Another learned to count in English "before counting in Bulgarian... by regularly watching Cindy Crawford's fitness videos with the mother (Slavova)."

Having parents who were diplomats gave opportunities to one person from Croatia to study English in different settings. According to Hofstede (2019), Bulgaria and Croatia have low scores in cultural dimension of individualism ranking 30 and 33, respectively, and are considered collectivistic, so a close long-term commitment to group and family members are highly valued. This finding is parallel with Tananuraksakul's (2009a) report on Asian students' personal insights into rich experiences gained when learning English in their homelands, that parents collectively play a vital role in their children's decision-making or future. The analysis suggests that students from the collectivist culture would be parentally aspired to value and study English.

Since attitude and motivation are intertwined concepts in learning a foreign language, three Bulgarian students reveal their intrinsic motivation in and positive attitudes toward learning English, which are strikingly similar to Slavova's (2018) study that Bulgarian students' "life revolves around the use of English through books, song lyrics, Internet articles, movies, international news broadcasts such as the BBC and CNN, multiplayer online games and communication with friends abroad" (p. 89). Others 
encompass "English is...my passion...I love various English accents, rich lexicology and...it is very pleasant to listen to (p. 88)..." Speaking English well "gives me the unique opportunity to communicate with people from all over the world as well as to become familiar with different cultures (p. 88)..." The analysis suggests that students in the present context also personally value English and learn it with intrinsic motivation and positive attitudes.

Theme two, which answers the second key research question, delves into the participants' social and academic journey in the present context. Despite the high levels of their standardized English proficiency, they experienced cultural and linguistic barriers which to an extent impacted on their psychological well-being. Five participants from Georgia, Kazakhstan, Bulgaria and Ukraine had academic culture shock (Li et al., 2010), possibly due to socio-linguistics they learned locally in their homeland and globally used in the present context.

Four participants from Bulgaria and Georgia faced an issue of unintelligibility in relation to words they used that were not recognized immediately (Smith \& Nelson, 2006). They had difficulty in understanding some professors and classmates whose pronunciation of English was different due to "a heavy accent." Unclear pronunciation even by someone from the same nation caused one student to be unfamiliar with the English accent. One student from Georgia encountered World Englishes shock, "a mental state of disorientation and frustration due to an exposure to alien varieties of English, which extended [a feeling of] insecurity" (Tananuraksakul, 2009, p. 49). Only two students from Bulgaria were able to overcome the barrier in a short period of time, yet none of those four expected their professors to accommodate their speech. Perhaps, it was because of 'high power distance' that those students culturally acquired and accepted a hierarchical order between them and their professors (Hofstede, 2019), further causing one participant from Bulgaria to feel uncomfortable, insecure and confused due to unfamiliarity with 'low power distance' the university practices. The emotional impacts lead to academic culture shock (Li et al., 2010). These outcomes reflected internal cultural aspects externally unobservable and embedded in the students' consciousness.

Like NNES students in Australian contexts, three participants from Bulgaria and Georgia appeared to encounter repetition shock because they were affected emotionally by being asked to repeat something they said (Tananuraksakul, 2009b, p. 49). However, empathy for intergroup members from NNES backgrounds prevented one Bulgarian participant from feeling repetition shock. The analysis firstly suggests that intergroup communication in this context marks a boundary between NNES speakers, near-native English speakers and native English speakers, and it mirrors their symbolic relations of power and identities (Norton, 2000). Secondly, the encounters of World Englishes shock and 
repetition shock may result from sociolinguistics the participants learned locally at home and used globally in the present context.

Two Bulgarian students were reluctant to talk to their professors during an appointment, while one person avoided speaking in the classroom. Across all cultures and social situations, individuals universally have "face" and a desire to maintain or attain it (Ting-Toomey, 1994). Ting-Toomey (2005) refers to 'competence' face as a desire to appear intelligent, accomplished and skillful whereas 'moral' face is the desire to appear dignified and honored. These two 'face' outlooks appeared to influence those participants' perceptions. However, a good rapport between professor and student helped one student achieve 'face'. These outcomes reflect internal cultural aspects not always easy to observe and embedded in some students' consciousness.

One Croatian participant particularly experienced a sense of social and academic exclusion and found it difficult to negotiate with multiple identities and lost confidence and dignity. However, this person's sense of academic inclusion was boosted during classroom discussion, which generated the desired linguistic and psychological identities. One Bulgarian participant attempted to exercise the skills of intercultural identity negotiation (Kim, 2001) when interacting with culturally different others with speech accommodation (Gile, 2008), trying to "say it better" or saying "whatever" or staying "silent."

\section{Conclusion, Implication, and Limitation}

This study qualitatively explores how NNES students value and experience the use of EGL in a Bulgarian higher education internationalization context where American educational systems and English as the media of instruction and communication are adopted. Two themes arise, which answer the research questions. The first theme discloses the participants' value of English at the exclusion of other languages, influenced by socio-cultural factors, such as parental, social and personal aspirations, since they were young in their homelands. The second theme indicates individual challenges of EGL use as well as social, academic and psychological adjustment in the present context.

Although the participants had adequate English proficiency, they tended to experience academic culture shock, World Englishes shock, and repetition shock, perhaps because sociolinguistics they learned locally at home and used globally in the present context. The high degree of 'power distance' they subconsciously brought with them and a sense of power relations and identity between them and native speakers additionally affected their adjustment. Despite these challenges, it appeared that they constructed and negotiated their multiple identities with mindfulness because they carried the positive achievement of learning the language (intrinsic and extrinsic motivation, attitudes, selfconfidence, and empathy) with them once stepping into new social and academic settings. 
It can firstly imply that students from NNES backgrounds in the present context can expect to experience academic culture shock, World Englishes shock, and repetition shock. Secondly, the positive effect in language learning can lead them to intercultural communication competence since Chang's (2013) research findings imply that mindfulness is the key of intercultural communication, and that knowledge or skills in language and culture can be "subsumed under mindfulness".

The small number of participants may limit this study, yet it offers insights into linguistic, cultural, and psychological challenges that students in the present context tend to encounter as well as determinants that impact their adjustment.

\section{Author Note}

I would like to express my deep gratitude to all the participants and those colleagues assisting me in data collection.

Currently, I am an Assistant Professor in the Department of Bilingual Education and English Language Teaching, Suryadhep Teachers College, Rangsit University, Thailand, with a PhD in Linguistics, Macquarie University, Australia. My research interests vary from English language teaching to mediated and non-mediated communication, to intercultural communication and to social psychology of use of English in different contexts.

\section{References}

Altbach, P. (2015). Perspectives on internationalizing higher education. International Higher Education, 27, 6-8. https://ejournals.bc.edu/index.php/ihe/article/view/6975

Altbach, P. (2016). Global perspectives on higher education. Johns Hopkins University Press.

Anderman, G., \& Rogers, M. (2005). English in Europe: For better, for worse? In G. Anderman \& M. Rogers (Eds.), In and Out of English: For Better, for Worse? (pp. 1-26). Multilingual Matters.

Arnold, J., \& Brown, D. (1999). A map of the terrain. In J. Arnold (Ed.), Affect in Language Learning (pp. 1-24). Cambridge University Press.

Bista, K., Sharma, G., \& Gaulee, U. (2018). International student mobility: Examining trends and tensions. In K. Bista (Ed.), International student mobility and opportunities for growth in the global marketplace (pp. 1-14). IGI Global. 
British Council. (2013). The English effect: The impact of English, what it's worth to the UK and why it matters to the world. https://www.britishcouncil.org/sites/default/files/english-effect-reportV2.pdf

Chang, Y. (2013). Never mind? Mindfulness and Competent Intercultural Interaction. Journal of Intercultural Communication, 32. https://www.immi.se/intercultural/nr32/yanrong.html

Corradi, A. (2017). The linguistic colonialism of English. Brown Political Review. https://brownpoliticalreview.org/2017/04/linguistic-colonialism-english/

Creswell, J. (2003). Research design: Qualitative, quantitative, and mixed methods approaches. Sage Publications.

Creswell, J. (2015). A concise introduction to mixed methods research. Sage Publications.

Ellis, R. (2011). The study of second language acquisition. Oxford University Press.

Giles, H. (2008). Communication accommodation theory. In L. Baxter \& D. Braithewaite (Eds.), Engaging theories in interpersonal communication: Multiple perspectives (pp. 161-173). Sage Publications.

Goffman, E. (1967). Interaction ritual: Essays on face-to-face behavior. Doubleday.

Hofstede, G. (2019). Hofstede Insights. https://www.hofstede-insights.com/

Jenkins, J. (2002). A sociolinguistically based, empirically researched pronunciation syllabus for English as an international language. Journal of Applied Linguistics, 23(1), 83-103.

Johnson, B., \& Christensen, L. (2012). Educational research: Quantitative, qualitative, and mixed approaches. Sage Publications.

Kachru, B. (1992). The other tongue: English across cultures. University of Illinois Press.

Khanal, J., \& Gaulee, U (2019). Challenges of international students from pre-departure to post study: A literature review. Journal of International Students, 9(2), 560-581. https://www.ojed.org/index.php/jis/article/view/673/699

Kim, Y. Y (2001). Becoming intercultural: An integrative theory of communication and cross-cultural adaptation. Sage.

Kreber, C. (2009). Different perspectives on internationalization in higher education. New Directions for Teaching and Learning, 118, 1-14.

Li, G., Chen, W., \& Duanmu, J. L. (2010). Determinants of international students' academic performance: A comparison between Chinese and other international students. Journal of Studies in International Education, 14(4), 389-405. https://core.ac.uk/download/pdf/397084.pdf 
Manakul, W. (2007). Role of English in internationalization of higher education: The case of the graduate school of engineering, Hokkaido University. Journal of Higher Education and Lifelong Learning, 15. https://high.high.hokudai.ac.jp/wp-content/uploads/2016/02/No1513.pdf

Norton, B. (2000). Identity and language learning: Gender, ethnicity and educational change. Pearson Education Limited.

Seidlhofer, B. (2012). Lingua franca English: The European context. In A. Kirkpatrick (Ed.), The Routledge Handbook of World Englishes (pp. 355-371). Routledge.

Slavova, E. (2018). Attitudes to English as a lingua franca and language teaching in a Bulgarian academic context. In Z. Tatsioka, B. Seidlhofer, N. Sifakis \& G. Ferguson (Eds.), Using English as a lingua franca in education in Europe: English in Europe (pp. 73-97). Walter de Gruyter.

Smith, L.E., \& Nelson, C.L. (2006). World Englishes and issues of intelligibility. In B. B. Kachru, Y. Kachru \& C.L. Nelson (Eds.), The handbook of world Englishes (pp. 428-444). Blackwell Publishing Ltd.

Spring, J. (2009). Globalization of education: An introduction. Taylor \& Francis.

Tananuraksakul, N. (2009a). An exploratory investigation of Asian students' sense of dignity in a nonnative English language learning context: A case study. Journal of Intercultural Communication, 19. https://www.immi.se/intercultural/nr19/noparat.htm

Tananuraksakul, N. (2009b). Unintelligibility: World Englishes shock and repetition shock in an Australian context. Prospect: An Australian Journal of TESOL, 24(2), 42-52. https://researchmanagement.mq.edu.au/ws/portalfiles/portal/16985393/mq10578Publisher+version+\%28open+access\%29.pdf

Tananuraksakul, N. (2010). An exploration of English as the medium and the message in the "Global Village": A case study. International Journal of Communication, 4, 914-931.

Tananuraksakul, N. (2012). Non-Native English students' linguistic and cultural challenges in Australia. Journal of International Students, 2(1),107-115. https://www.semanticscholar.org/paper/NonNative-English-Students\%27-Linguistic-and-inTananuraksakul/f0adc37fbead9e2d70d801d353f41e96046c79c8?p2df

Tananuraksakul, N. (2015). Interrelationship between linguistic identity, perception, psychological wellbeing and context: Use of global English in an Australian context. Journal of Applied Linguistics, 6(2), 143-163. 
The Organisation for Economic Cooperation and Development. (2013). How many students study abroad and where do they go?. Education at a Glance 2013: Highlights, OECD Publishing, Paris. https://doi.org/10.1787/eag_highlights-2013-12-en

The Sophia Globe. (2018). Bulgaria Ranks $25^{\text {th }}$ in the World in English Proficiency Index - Report. https://sofiaglobe.com/2018/11/26/bulgaria-ranks-25th-in-the-world-in-english-proficiencyindex-report/

Thornborrow, J. (2004). Language and identity. In I. Singh \& J. S. Peccei (Eds.), Language, society and power: An introduction (pp. 157-172). Routledge.

Ting-Toomey, S. (2005). The matrix of face: An updated face-negotiation theory. In W. Gudykunst (Ed.), Theorizing about intercultural communication (pp. 71-92). Sage Publications.

Vasileva, B. (2008). Some aspects of intercultural training of Bulgarian learners of English. BETA-IATEFL. https://www.beta-iatefl.org/1688/blog-publications/some-aspects-of-intercultural-training-ofbulgarian-learners-of-english/

Wells, A. (2014). International student mobility: Approaches, challenges and suggestions for further research. Social and Behavioral Sciences, 143, 19-24. https://www.sciencedirect.com/science/article/pii/S1877042814042785

Yano, Y. (2018). Communication in English as a lingua franca: The Kachruvian model of three circles reconsidered. In E. L. Low \& A. Pakir (Eds.), World Englishes: Rethinking Paradigms (pp. 96-113). Routledge. 